University of Wollongong

Research Online

Faculty of Social Sciences - Papers (Archive) Faculty of Arts, Social Sciences \& Humanities

2013

How physically active are children attending summer day camps?

Michael W. Beets

University of South Carolina, beets@mailbox.sc.edu

Robert G. Weaver

University of South Carolina

Aaron Beighle

University of Kentucky

Collin Webster

University of South Carolina, cwebster@uow.edu.au

Russell R. Pate

University of South Carolina

Follow this and additional works at: https://ro.uow.edu.au/sspapers

Part of the Education Commons, and the Social and Behavioral Sciences Commons

Research Online is the open access institutional repository for the University of Wollongong. For further information contact the UOW Library: research-pubs@uow.edu.au 


\title{
How physically active are children attending summer day camps?
}

\begin{abstract}
Background: Summer day camps (SDC) represent one of the largest settings, outside the academic school year, where children can engage in safe, enjoyable physical activity (PA). Yet, little is known about this setting and how active children are while attending. Methods: System for Observing Play and Leisure Activity in Youth was used to categorize PA of boys/girls as Sedentary/Walking/Vigorous across multiple days (8 AM to 6 PM) in 4 large-scale community-based SDCs. Contextual characteristics of type of activity, activity management, equipment, and in/outdoors were collected simultaneously; Mixed-model regression analyses examined associations between PA categories and contextual characteristics. Results: A total of 4649 scans of 2462 children were made across 27 days in the SDCs. Physical activity opportunities represented $38 \%$ of the daily schedule. Overall, $74 \%-79 \%, 13 \%-16 \%$, and $7 \%-9 \%$ of children were observed Sedentary, Walking, or Vigorous during the SDC, and this changed to $62 \%-67 \%, 18 \%-19 \%$, and $15 \%-18 \%$ observed Sedentary, Walking, or Vigorous during PA opportunities. Water-based PA, equipment, and free-play were related to increased PA. Children waiting-in-line for turns, staff instructing, and organized PA were related to increased sedentary. Conclusions: These findings provide evidence of modifiable characteristics of SDCs associated with PA. Improving staff skills related to facilitating active environments is a viable avenue to increase PA accumulated within SDCs.
\end{abstract}

\section{Keywords}

summer, camps, day, attending, children, physically, active

\section{Disciplines}

Education | Social and Behavioral Sciences

\section{Publication Details}

Beets, M. W., Weaver, R. G., Beighle, A., Webster, C. \& Pate, R. R. (2013). How physically active are children attending summer day camps?. Journal of Physical Activity and Health, 10 (6), 850-855. 


\title{
How Physically Active Are Children Attending Summer Day Camps?
}

\author{
Michael W. Beets, Robert G. Weaver, Aaron Beighle, Collin Webster, and Russell R. Pate
}

\begin{abstract}
Background: Summer day camps (SDC) represent one of the largest settings, outside the academic school year, where children can engage in safe, enjoyable physical activity (PA). Yet, little is known about this setting and how active children are while attending. Methods: System for Observing Play and Leisure Activity in Youth was used to categorize PA of boys/girls as Sedentary/Walking/Vigorous across multiple days (8 AM to 6 PM) in 4 large-scale community-based SDCs. Contextual characteristics of type of activity, activity management, equipment, and in/outdoors were collected simultaneously: Mixed-model regression analyses examined associations between PA categories and contextual characteristics. Results: A total of 4649 scans of 2462 children were made across 27 days in the SDCs. Physical activity opportunities represented $38 \%$ of the daily schedule. Overall, $74 \%-79 \%, 13 \%-16 \%$, and $7 \%-9 \%$ of children were observed Sedentary, Walking, or Vigorous during the SDC, and this changed to $62 \%-67 \%, 18 \%-19 \%$, and $15 \%-18 \%$ observed Sedentary, Walking, or Vigorous during PA opportunities: Water-based PA, equipment, and free-play were related to increased PA. Children waiting-in-line for turns, staff instructing, and organized PA were related to increased sedentary. Conclusions: These findings provide evidence of modifiable characteristics of SDCs associated with PA. Improving staff skills related to facilitating active environments is a viable avenue to increase PA accumulated within SDCs.
\end{abstract}

Keywords: community, obesity, policy, out-of-school-time

Summer vacation represents an important time away from the school setting for children. During this break, children have a large amount of free time and are typically igvolved in a wide variety of formal and informal activities, spend time with friends and family, and travel. Yet for many children, summer vacation also represents a period of time when declines in health occur. During this time (typically June to August) ${ }^{l}$ children gain a larger amount of body weight compared with the amount gained over the school year ${ }^{2}$ and weight gain during summer reverses weight losses achieved during school. ${ }^{3}$ Moreover, schoolbased interventions have observed substantial declines in fitness after the 3 month summer break, erasing any gains made during the school-year. ${ }^{4,5}$

Serving over 14.3 million youth, ${ }^{6}$ summer day camps (SDC) represent one of the largest settings, outside of the regular school academic year, where physical inactivity and childhood obesity can be addressed. Summer day camps often last 8-10 hrs/day, span the entire summer vacation, and include a wide assortment of activities scheduled each day (ie, they do not focus on a single activity, as

Beets and Pate are with the Dept of Exercise Science, University of South Carolina, Columbia, SC. Weaver and Webster are with the Dept of Physical Education, University of South Carolina, Columbia, SC. Beighle is with the Dept of Kinesiology and Health Promotion, University of Kentucky, Lexington, KY. do specialty sports or music camps). During a typical day, children attending a SDC be involved in enrichment- (eg, arts and crafts), theater-, and academic-related (eg, science) activities, as well as opportunities to be physically active (eg, water-based activities, field games).

Summer day camps represent a natural extension of health and wellness efforts that target children during the school year. In a 2011 national study of emerging issues faced by summer camp leaders, the American Camp Association ${ }^{7}$ reported that camp staff identified "nutrition and PA of the children attending" as the third most important issue facing SDCs, behind "financial security of the camp" and "communication to parents." Moreover, national standards for physical activity within SDCs have recently been developed, ${ }^{8}$ supporting this as a setting where meaningful amounts of physical activity can be accumulated. Importantly, while these standards are referred to as "evidence-based," none of the evidence cited is based on data collected within the SDC environment.

Summer day camps are an important communitybased program that can promote healthy lifestyles of children outside of the school/academic calendar. At this time, little is known about the amount of physical activity children accumulate or what modifiable contextual characteristics are associated with activity within SDCs. Therefore, the purpose of this study was to describe the activity levels of children attending SDCs and examine 
the association of modifiable contextual characteristics that could be targeted in future interventions.

\section{Methods}

\section{Participants and Setting}

Four large-scale SDCs in the Columbia, SC metropolitan area were recruited and took part in this study. These SDCs each served approximately 200 children per day each, the majority of whom were 12 years and younger. The data presented here represent baseline evaluations from an intervention targeting physical activity and nutrition. Due to the observational nature of the data collection, passive consent was obtained by the SDCs, their frontline-staff, and the parents enrolling their children in the programs. All procedures were approved by the university's institutional review board.

The camp schedule of activities officially began at $9 \mathrm{AM}$ and lasted until 4 to 4:30 PM. The SDCs allowed parents to drop-off their children at 7 AM to 7:30 AM and pick-up their children no later than 6 PM each day. Before the camp started ( 7 AM to 9 AM) and after it ended ( 4 PM to $6 \mathrm{PM}$ ) children participated in unstructured activity. The SDCs were open all summer and parents were allowed to enroll their children in the SDCs for a week (Monday through Friday) or more at a time. In the SDCs children were grouped by age (K-1st, 2 nd-3rd, 4th-5th) with a staff-to-student ratio of $1: 10$. Across the 4 SDCs approximately $25 \%-35 \%$ of the children attending received discounted pricing or a scholarship to attend.

The SDCs offered a wide range of activities for the children to participate in daily. Hence, the SDCs were not specialty camps that focused on single activities. These included water-based activities such as swimming in a pool, playing at a water park, or splash pad (ie, concrete pad with water fountains), free-play opportunities, organized physical activities such as basketball and elimination games (eg, dodgeball), and enrichment activities such as arts and crafts. Each SDC had access to large outdoor green spaces, indoor play spaces (eg, gymnasiums, large rooms), and water-based activities (eg, pool, lake, splash pad). All data were collected during the summer of 2011. The average daily low and high temperatures during data collection were $74^{\circ} \mathrm{F}$ (range $68-79^{\circ} \mathrm{F}$ ) to $96^{\circ} \mathrm{F}$ (range $88-102^{\circ} \mathrm{F}$ ), respectively. During data collection, the average daily rain fall was 0.08 inches.

\section{Physical Activity and Contextual Characteristics}

Physical activity was measured via direct observation using the System for Observing Play and Leisure Activity in Youth. ${ }^{9}$ SOPLAY is designed to measure physical activity in groups as well as the social and environmental contexts in which those behaviors occurred. ${ }^{9}$ It is based on momentary time sampling in which scans of individuals and contextual factors are made within target areas. Trained research assistants conducted the scans mechanically using a tally counter (The Denominator Company, Woodbury, CT). All potential areas for direct observation (ie, activity areas) at the SDC sites were identified and measured before data collection (location, size, and boundaries). Summary counts were made for the number of children in 3 categories; Sedentary (lying down, sitting, or standing), Walking, or Vigorous in each area scanned. Scans were made from left to right separate for boys and girls. The number of boys/girls sedentary, walking, or vigorous during a single scan was transformed into a percentage by taking the number of children observed in each behavior category and dividing this by the total number of children observed in the scan (ie, sum of children observed sedentary, walking, or vigorous). The percentage variables were used in all analyses (see below).

The SDCs were observed for the entire day (7:30 AM to $6 \mathrm{PM}$ ) by multiple trained observers who observed in shifts lasting 4-6 hours. During this time, observers took 2 15-minute breaks and 130 -minute lunch break throughout the day. Immediately after each scan for either boys or girls physical activity, the following contextual information was recorded: type of scheduled activity: assembly, drop-off or pick-up, snack/lunch, physical activity, enrichment, or bathroom/changing; activity context: presence of physical activity-related equipment (eg, balls, hula-hoops), whether the activity was waterbased (eg, swimming pool, splash pad, water park), either free-play or organized, if the activity took place outdoors or indoors; staff management of the physical activities: staff providing instructions (ie, frontline-staff are giving instructions, other than PA instructions, to children), children idle (ie, children are not engaged in any specific activity and are awaiting instructions from frontlinestaff), children waiting-in-line for turn (ie, children stand and wait their turn to play/participate in PA.), elimination games, whether 2 or more activities were offered; and age group observed: $\mathrm{K}-1$ st grade, 2 nd-3rd grade, 4 th-5th grade, and mixed age group (presence of 2 or more age groups together). In addition, the total number of staff was recorded. These contextual characteristics were based on policy and standards documents that outline best practices and core competencies for out-of-school-time program staff and environment ${ }^{8,10-12}$ and reflect modifiable and the most proximal influencers on children's physical activity in out-of-school-time programs (eg, afterschool programs and summer day camps). ${ }^{11,13}$

\section{Observer Training and Reliability}

Research assistants were initially trained using the Systematic Observation CD provided by Active Living Research (Dr. Thom McKenzie presents Systematic Observation: SOPLAY/SOPARC, November 2005). In addition, observers spent 2 weeks, before data collection, in out-of-school-time programs establishing reliability of physical activity and contextual characteristics. Consistent with previous studies, reliability was collected throughout the study during 8 of the $27(30 \%)$ of the measurement days. ${ }^{14}$ 


\section{Analyses}

Initially, descriptive statistics were calculated for all variables. Interrater reliability of continuous variables (ie, number of children observed in each physical activity category and overall) was estimated using intraclass correlation coefficient (ICC) and paired $t$ tests. The interrater reliability of dichotomous variables of the SDC contextual characteristics was estimated using percent agreement. Three-level random effects models with scans nested within days nested within SDCs were used to examine the association of contextual characteristics with the percentage of boys and girls, separately, observed sedentary, walking, or vigorous. All analyses were conducted using STATA (v.12.0, College Station, TX).

\section{Results}

Overall, a total of 4649 scans were made on 2462 children across 27 days in the 4 SDCs. The reliability of the continuous variables ranged from ICC 0.86 (vigorous) to 0.98 (sedentary) and the percent agreement of the dichotomous variables ranged from $79 \%$ (kids wait-in-line for turn) to 93\% (2 or more activities offered). Overall, the proportion of boys and girls observed sedentary, walking, or in vigorous physical activity was $74.2 \%, 16.4 \%$, and $9.4 \%$; and $79 \%, 13.5 \%$, and $7.5 \%$, respectively. The percentage of children observed in each physical activity category by scheduled activity is presented in Table 1 . The percentage of observations for the contextual characteristics is presented in Table 2. Across the observations, time allocated for physical activity opportunities was the most prevalent (38\% of SDC schedule), followed by enrichment, and drop-off/pick-up times. The associations of contextual characteristics are presented in Table 3. Not unexpectedly, boys and girls were most active (walking and vigorous) during scheduled physical activity time in comparison with all other scheduled activities. For activity context variables, the presence of equipment and scheduled free-play time was associated with a decrease in the proportion of boys and girls observed sedentary, while water-based activities were associated with an increase in the proportion of boys/girls observed in vigorous activity. Interestingly, being outdoors was associated with a decrease in the proportion of boys/girls observed in vigorous activity and an increase in children observed walking. For staff management of physical activity, giving instruction and having children waiting-in-line for turns were each associated with increases in sedentary behavior. Conversely, the presence of elimination games and 2 or more physical activity choices were associated with decreased sedentary behavior. There was no influence of age group on activity levels.

\section{Discussion}

Summer day camps represent a setting, outside the school academic calendar year where children can be exposed to health enhancing environments. This is echoed in recently developed standards for promoting physical activity in SDCs. ${ }^{8}$ Our findings indicate that while a substantial proportion of time is allocated for physical activity in the SDC schedule $(-38 \%)$, the majority of children are not physically active during this time. Likewise, during the remaining $60 \%$ of the daily schedule, well over $80 \%$ of children are observed sedentary. Thus, while SDCs can serve as a healthy-bridge between school years (Spring to Fall), they are not fully capitalizing on opportunities to provide physical activity for children.

Staff represent one of the most critical, modifiable (ie, trainable), and proximal elements that influence children's physical activity in out-of-school-time programs. ${ }^{11,13}$ The findings from this study indicate that how staff manage physical activity opportunities has a substantial impact on the proportion of children observed physically active. For instance, when children were provided with 2 or more physical activity options, children were more physically active (decrease in sedentary behavior by $7 \%-11 \%$ ). Conversely, when children had to wait-in-line for a turn the percentage of children observed sedentary increased by $6 \%-7 \%$. These 2 management practices can

Table 1 Percentage of Boys and Girls ( $N=2,462)$ Observed Physically Active by Scheduled Activity Across 4649 Scans in 4 Summer Day Camps

\begin{tabular}{lccccccc}
\hline & \multicolumn{5}{c}{ Percentage of children in each physical activity category } \\
\cline { 2 - 4 } \cline { 7 - 8 } Scheduled activity & \multicolumn{3}{c}{ Boys } & & \multicolumn{3}{c}{ Girls } \\
\cline { 2 - 4 } \cline { 6 - 8 } & Sedentary & Walking & Vigorous & & Sedentary & Walking & Vigorous \\
\hline Enrichment & 89.6 & 8.2 & 2.2 & & 92.5 & 6.4 & 1.0 \\
Physical activity & 62.1 & 19.6 & 18.3 & & 66.7 & 17.9 & 15.4 \\
Snack/lunch & 83.3 & 14.5 & 2.2 & & 85.9 & 12.0 & 2.1 \\
Bathroom/changing & 83.7 & 13.7 & 2.6 & & 86.2 & 11.8 & 2.0 \\
Drop-off/pick-up & 67.8 & 24.4 & 7.7 & & 78.1 & 15.9 & 6.0 \\
Assembly & 83.3 & 13.3 & 3.4 & & 85.1 & 12.3 & 2.5 \\
Other & 86.8 & 11.0 & 2.2 & & 89.5 & 7.7 & 2.9 \\
\hline
\end{tabular}


Table 2 Descriptive Characteristics of Contextual Characteristics in 4 Summer Day Camps

\begin{tabular}{|c|c|c|}
\hline & $\begin{array}{l}\text { \% total observations } \\
\qquad(\mathrm{N}=4649)\end{array}$ & $\begin{array}{l}\text { \% observations during } \\
\text { physical activity time } \\
(n=1855)\end{array}$ \\
\hline \multicolumn{3}{|l|}{ Scheduled activity } \\
\hline Enrichment & 17.7 & \\
\hline Physical activity & 38.5 & \\
\hline Snack/lunch & 12.8 & . \\
\hline Bathroom/changing & 10.0 & \\
\hline Drop-off/pick-up & 12.5 & \\
\hline Assembly & 4.4 & \\
\hline Other & 4.1 & \\
\hline \multicolumn{3}{|l|}{ Activity context ${ }^{\dagger}$} \\
\hline Presence of equipment & 30.7 & 54.3 \\
\hline Water-based physical activity & 13.9 & 33.9 \\
\hline Free-play physical activity (vs. organized physical activity) & 26.2 & 39.5 \\
\hline Outdoor location (vs. indoor location) & 43.7 & 53.6 \\
\hline \multicolumn{3}{|l|}{ Staff management of physical activities ${ }^{\dagger}$} \\
\hline Staff giving instructions & 8.4 & 12.1 \\
\hline Idle time & 59.1 & 52.2 \\
\hline Children standing in line for turn & 10.9 & 24.4 \\
\hline Elimination game & 5.8 & 13.0 \\
\hline Two or more physical activities provided (choice) & 4.8 & 7.8 \\
\hline \multicolumn{3}{|l|}{ Children age groups $^{\dagger}$} \\
\hline Kindergarteners and Ist graders & 27.1 & 25.9 \\
\hline 2nd and 3 rd graders & 31.9 & 33.7 \\
\hline 4th and 5th graders & 24.8 & 29.9 \\
\hline Mixed age group & 33.5 & 32.9 \\
\hline Average number of staff present & 3.5 & 3.9 \\
\hline Average number of boys/girls present & 12.8 & 12.7 \\
\hline
\end{tabular}

$\dagger$ Percentages do not sum to $100 \%$ due to more than 1 item present. in each scan.

easily be addressed in staff training to either be enhanced (ie, planning 2 or more activities to offer during physical activity time) or minimized (ie, removal of lines from games) ${ }^{12}$ and have the ability to increase physical activity. Interestingly, elimination games were associated with an increase in physical activity for both boys and girls. Based on our observations, the children enjoyed these types of games and therefore may have wanted to be involved, and thus, more active while playing. In addition, the SDCs had limited equipment available during these games ( $\sim 50 \%$ of the time) making being "eliminated" more difficult, thereby extending the amount of time children played. While elimination games have widely been condemned, ${ }^{8}$ they can and should be modified to exclude elimination, yet retain the enjoyable elements of the game. ${ }^{12}$ For instance, instead of elimination, rules could be modified to have 2 teams, whereby both teams try to catch balls thrown to different sides, whereupon once a ball is caught, the thrower has to go to the other team. The winner of this game would be the group with the largest team at the end of the game. These simple modifications can ensure activities are offered that children enjoy while also focusing on maximizing participation.

The findings that outdoor activity was associated with a reduction in the percentage of children observed in vigorous physical activity and a corresponding increase in the percentage of children observed walking may have been due to temperatures during the summer. As mentioned previously, the range of average temperature across the 27 days of observation was $74^{\circ} \mathrm{F}$ in the mornings to $96^{\circ} \mathrm{F}$ in the afternoons. However, outdoor activity was scheduled during the morning when temperatures were cooler. Thus, it is unclear why children were less vigorously active outdoors versus indoors. Not surprisingly, 


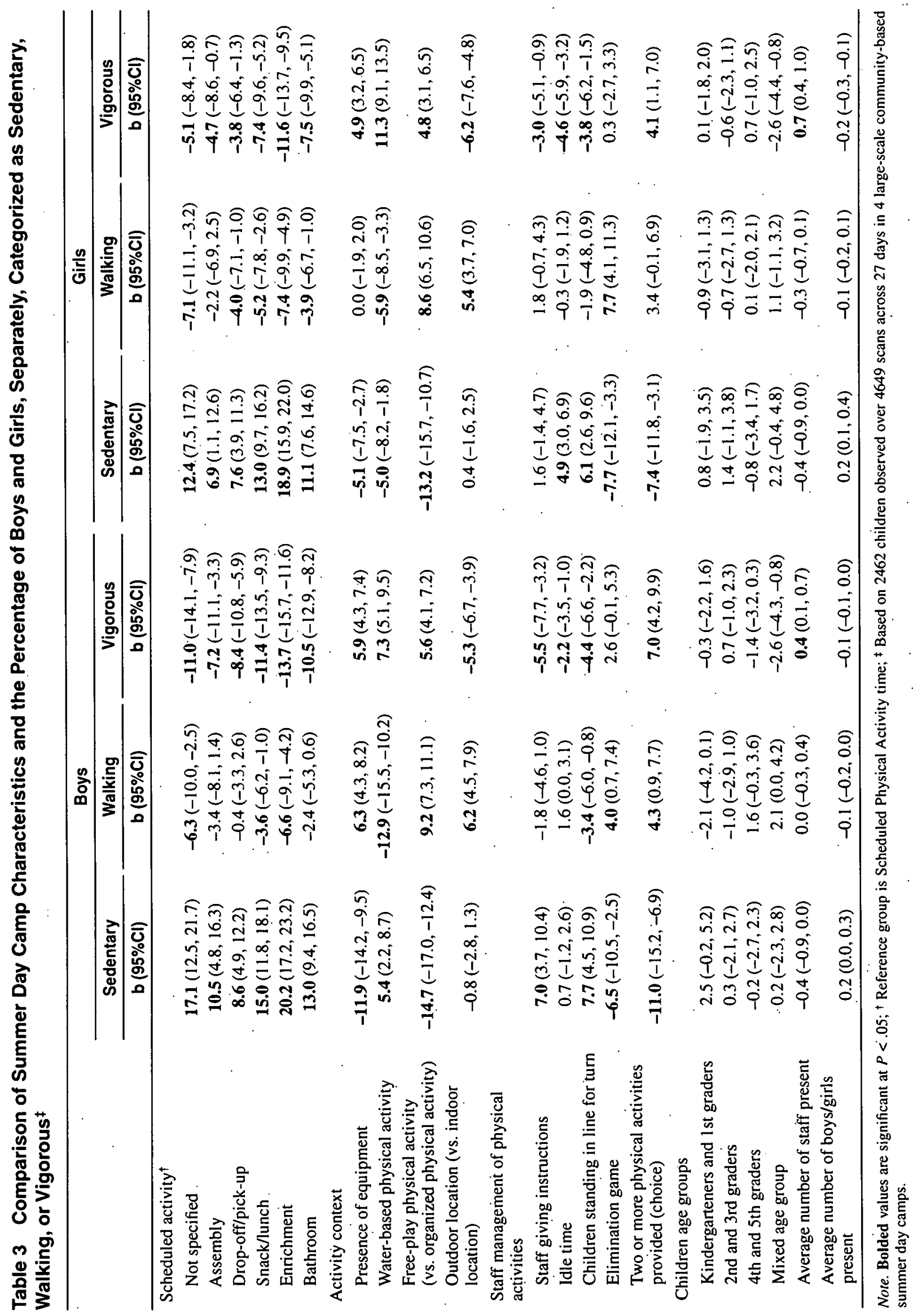


water-based activities were associated with an increase in vigorous physical activity for both boys and girls. Given the daily temperatures, this type of activity is clearly one of the more enjoyable. The proportion of time allocated to water-based activities, however was only $33 \%$ of the physical activities offered (see Table 2). This was due. to limited space in the water activity areas (eg, pools, splash pad) to safely accommodate all children. Thus, children were allowed only a small portion of their day to play with/in water. Building additional time into the daily schedule for water-based activities that do not require substantial resources (eg, pool facilities) such as sprinklers or water guns/balloons might help to increase physical activity.

Several limitations of this study need to be noted. First, only 4 community-based SDCs were included in this study, limiting the ability to generalize to other SDCs across the country. We attempted to identify characteristics of existing SDCs, but were unable to locate any local, state, or national information to make comparisons. Thus, it is unclear if other SDCs are providing more or less physical activity in comparison with those in this study. However, the SDCs did have substantial resources to promote physical activity (adequate outdoor/indoor spaces), suggesting that if other SDCs do not have similar facilities then it is likely activity levels would be lower. Second, the systematic observation tool, while widely used, cannot provide an estimate of minutes spent in physical activity. Hence, this study cannot determine whether children were meeting physical activity guidelines or the contribution of SDCs to total daily physical activity. However, one study ${ }^{15}$ reported that children who wore accelerometers for $\sim 6$ hrs while attending SDCs across 3 states (HW, KY, SC) accumulated an average of 20 minutes of moderate-to-vigorous physical activity during nonwater-based activities. These estimates are consistent with our findings from direct observation. The use of SOPLAY was made based on the inability to capture physical activity via motion sensors (pedometers, heart rate, accelerometers) during water-based activities.

In conclusion, this study represents some of the first information on the SDC setting and indicates SDCs are strongly positioned to provide children with meaningful amounts of physical activity during the summer vacation months. However, the SDCs in this study were failing to capitalize on this largely due to staff behaviors and management of activity opportunities. Future research needs to examine if limited physical activity involvement is occurring in SDCs in different locations around the country. Strategies to train staff in creating physical activity friendly environments must also be evaluated. This will allow SDC's to bridge the physical activity gap between school years (ie, summer vacation) and to meet policy mandates that have recently been adopted.

\section{References}

I. Wikipedia. Summer Vacation. 2011; en.wikipedia.org/ wiki/Summer_vacation. Accessed August 8th, 2011.

2. von Hippel PT, Powell B, Downey DB, Rowland NJ. The effect of school on overweight in childhood: gain in body mass index during the school year and during summer vacation. Am J Public Health. 2007;97(4):696-702. doi:10.2105/AJPH.2005.080754

3. Gillis L, McDowell M, Bar-Or O. Relationship between summer vacation weight gain and lack of success in a pediatric weight control program. Eat Behav. 2005;6(2):137143. doi:10.1016/j.eatbeh.2004.08.002

4. Carrel AL, Clark RR, Peterson S, Eickhoff J, Allen DB. School-based fitness changes are lost during the summer vacation. Arch Pediatr Adolesc Med. 2007;161(6):561564. doi:10.1001/archpedi.161.6.561

5. Gutin B, Yin Z, Johnson M, Barbeau P. Preliminary findings of the effect of a 3-year after-school physical activity intervention on fitness and body fat: The Medical College of Georgia Fitkid Project. International Journal Of Pediatric Obesity: IJPO: An Official Journal Of The International Association For The Study Of Obesity. 2008;3(Suppl 1):3-9. doi:10.1080/17477160801896457

6. After A. 3 PM. Special report on summer: missed opportunities, unmet demand. Washington, DC: Afterschool Alliance; 2010.

7. American Camp Association. 2011 Camp Emerging Issues Survey. 2011 ; http://www.acacamps.org/research/improve/ emerging-issues. Accessed August 8th, 2011.

8. Wiecha JL, Gannett L, Hall G, Roth BA. National Afterschool Association Standards for Healthy Eating and Physical Activity in Out-Of-School Time Programs. 2011; www.niost.org. Accessed August 8th, 2011.

9. McKenzie TL, Marshall SJ, Sallis JF, Conway TL. Leisure-time PA in school environments: an observational study using SOPLAY. Prev Med. 2000;30(1):70-77. doi:10.1006/pmed.1999.0591

10. Beets MW, Wallner M, Beighle A. Defining standards and policies for promoting physical activity in afterschool programs. J Sch Health. 2010;80(8):411-417. doi: $10.1111 / j .1746-1561.2010 .00521 . x$

11. Beets MW, Webster C, Saunders R, Huberty JL. Translating policies into practice: a framework for addressing childhood obesity in afterschool programs. Health Promot Pract. 2013; 14(2):228-237.

12. Weaver RG, Beets MW, Webster C, Beighle A, Huberty JL. A conceptual model for training afterschool program staffers to promote physical activity and nutrition. Journal of School Health. 2012;82(4): 186-195.

13. Beets $M W$. Enhancing the translation of physical activity interventions in afterschool programs. American Journal of Lifestyle Medicine. 2012;6(4):328-341.

14. McKenzie TL, Marshall SJ, Sallis JF, Conway TL. Leisuretime physical activity in school environments: an observational study using SOPLAY. Prev Med. 2000;30(1):70-77. doi:10.1006/pmed.1999.0591

15. Beets MW, Morgan CF, Banda JA, et al. Convergent validity of pedometer and accelerometer estimates of moderate-to-vigorous physical activity of youth. $J$ Phys Act Health. 2011 ;8(Suppl 2):S295-S305. 
Copyright of Journal of Physical Activity \& Health is the property of Human Kinetics Publishers, Inc. and its content may not be copied or emailed to multiple sites or posted to a listserv without the copyright holder's express written permission. However, users may print, download, or email articles for individual use. 